\title{
Análise de Sites em Geociências e Difusão de Materiais Didáticos na Internet
}

\author{
Celso Dal Ré Carneiro (cedrec@ige.unicamp.br) e André Henrique \\ Departamento de Geociências Aplicadas ao Ensino - Instituto de Geociências - UNICAMP \\ Caixa Postal 6.152, CEP 13083-970, Campinas, SP, BRA
}

Recebido em 19 de dezembro de 2003; aceito em 18 de novembro de 2004

Palavras-chave: Internet, ensino de Geociências, Geociências, análise de websites, sítios web.

\section{RESUMO}

A Internet oferece importantes ferramentas na busca de informações, aplicativos e auxílio pedagógico em quaisquer áreas de interesse, podendo ser utilizada tanto por educadores quanto por alunos no intuito de enriquecer o processo ensinoaprendizagem. A partir desse paradigma, a pesquisa buscou desenvolver e aplicar uma análise sistemática de websites para Educação em Geociências, área na qual se notam deficiências na disseminação de conteúdo regional e, sobretudo, baixo aproveitamento didático da informática. Para aperfeiçoar as técnicas de disponibilização de informações geológicas e geomorfológicas regionais, foi construído um Banco de Dados que armazena dados de diversos indicadores de avaliação. A análise de websites propicia uma visão crítica a respeito da acuidade visual, da qualidade do conteúdo informativo e das alternativas utilizadas para exibição. Os resultados indicam a existência de websites excelentes nos campos de Geologia, Geomorfologia e outros segmentos das Geociências. Um bom website educacional, além de permitir navegação fácil e agradável pelo universo on-line, deve ser continuamente atualizado e deve conter ferramentas que estimulem a interatividade e a curiosidade, como gráficos, animações e hipertextos. Assim, o Banco Analítico de Dados construído pode ser um guia, para educadores e alunos, no acesso aos mais interessantes websites ligados às Geociências, na medida em que se enfatizam os recursos mais bem aproveitados em cada um deles.

Keywords: Internet, Geoscience learning, website analysis.

\begin{abstract}
The Internet provides information search tools, softwares and important pedagogical aids for the Geosciences. These tools may be used both by teachers and students as a means to enhance the teaching-learning process. To better understand Internet contents for the Geosciences in Brazil and to provide a guide to what is available and its quality, we selected websites deemed useful for Education in Geosciences. This is an area where deficiencies in the dissemination of regional content and low use of Internet tools are known. Such systematic analysis can profitably optimize techniques of making regional geological and geomorphological information available. It effectively provides a critical assessment of the visual characteristics, the quality of information, and the display alternatives of the websites. The results of the analysis were used to create a data base on Internet resources according to many evaluation indicators. A good educational website should allow pleasant and easy navigation within the on-line universe, it should be up-to-date, and it should contain tools - such as graphics, animated clips and hypertexts - that stimulate interaction and curiosity. Our study documents the existence of both good and bad websites in the fields of geology, geomorphology and other branches of the Geosciences. Both educators and students will find the data base created from the analysis to be an excellent guide to the most interesting websites on Geosciences.
\end{abstract}




\section{INTRODUÇÃO}

A Internet representa, para as Geociências, uma ferramenta essencial na busca de informações, aplicativos e auxílio pedagógico. A exemplo do que ocorre em outras áreas do conhecimento, ela se revela uma "ferramenta de trabalho intelectual” (Ferrés, 2002) tão eficaz quanto os softwares educacionais, com a vantagem de ser mais dinâmica, possuir conteúdo flexível e isentar-se dos custos de distribuição física do material. As Geociências, atualmente, são beneficiadas, em comparação com outros campos da Ciência, pela volumosa aquisição de novas informações e pela profícua dispersão de modelos, animações e imagens por meio da grande rede. Não obstante, essa área do conhecimento é afetada por três fatores críticos:

a. o deficiente aproveitamento da Informática nas escolas;

b. a dificuldade de acesso às Geociências pelas pessoas em geral devido à falta de base conceitual;

c. a insuficiente disseminação, no Brasil, de dados geológicos regionais.

Considerando-se que o uso do computador nas atividades de ensino-aprendizagem vem aumentando significativamente nos últimos anos, a presente nota busca avaliar a disponibilidade de informações geocientíficas na rede mundial de computadores, a Internet. Em uma primeira tentativa buscou-se responder a algumas questões:

1. Quais são as características do conteúdo didático de Geociências disponível em websites?

2. Qual sua importância e utilidade para os níveis de ensino fundamental, médio e superior?

3. Seria conveniente que fosse estabelecida uma forma padronizada para selecionar websites e analisá-los, com a finalidade de avaliar a abrangência, utilidade e confiabilidade do conteúdo veiculado?

4. É viável classificá-los segundo a natureza da informação e indicar a faixa escolar mais apropriada para seu uso?

Embora o desafio seja dificultado pela rapidez de atualização dos websites disponíveis na rede, a resolução parcial desses problemas permitiria entender melhor a dinâmica de produção de sítios geocientíficos - ainda que restrita a uma efêmera "fotografia" - e esboçar uma avaliação quantitativa da disponibilidade de conteúdo didático na rede mundial. O presente artigo busca coletar esses elementos e estabelecer critérios para avaliação de websites relacionados às Geociências, por meio de um levantamento teórico-bibliográfico e na navegação sistemática em sítios de conteúdo relacionado a algum ramo das Geociências. Admitiu-se, portanto, que o trabalho tenha dupla função no que se refere à difusão de materiais didáticos na Internet. A primeira inclui a criação de metodologia de avaliação e classificação - uma espécie de ranking - contendo os melhores e mais completos websites de conteúdo relacionado às Geociências disponíveis na grande rede, com ênfase naqueles em português e dando destaque às principais características de cada um deles. O segundo propósito do trabalho é definir critérios qualitativos que devam ser assumidos em todo processo de desenvolvimento e disseminação de conteúdo educacional em meio digital, possibilitando a utilização da Internet como ferramenta que auxilie os educadores de forma eficiente, sendo agradável e atraente aos aprendizes.

O método de trabalho utilizado para a execução da pesquisa consistiu essencialmente na elaboração de um instrumento que servisse de base para coleta e armazenamento das informações provenientes da análise e avaliação de websites. Para tanto foram construídos um Banco Analítico de Dados e uma planilha para atribuição de conceitos que possibilitaram estabelecer comparações entre os websites de acordo com critérios preestabelecidos. O "trabalho de campo" consistiu propriamente na "navegação" sistemática em websites relacionados às Geociências.

\section{FUNDAMENTOS TEÓRICOS}

\section{Internet e Educação}

A utilização do computador na educação provoca impactos significativos nas atividades de ensino-aprendizagem. Inicialmente, seu uso fôra restrito a uma versão computadorizada dos métodos de ensino atuais, mas, como qualquer ferramenta, também sofre a tendência de desenvolver seus métodos próprios (Valente, 1993). É a partir daí que suas potencialidades têm maior aproveitamento e um novo paradigma se instala.

Seja pelo alto grau de motivação que provoca nos alunos ou pela facilidade de acesso às informações, a utilização do computador na Educação possui incontáveis aplicações dentro e fora da sala-de-aula (Carneiro, 2002), e estas podem ser valorizadas em qualquer área do ensino. É absolutamente impossível listar as inúmeras finalidades que o computador assume em Geociências. Para possibilitar a análise ora proposta - avaliar a disponibilidade de informações geocientíficas na Internet - esta nota restringe-se àquelas finalidades relacionadas ao uso do computador como meio de acesso a informações e dados externos por meio da Internet e como auxílio na produção de material didático.

Quando se fala em Internet, automaticamente imaginase um universo de informações de todas as áreas do conhecimento, um espaço rico e democrático, mas ao mesmo tempo mal-organizado e confuso. A busca de informações 
confiáveis em meio ao imenso volume de dados é cada vez mais complexa e requer tempo e treinamento (Macedo, 2002). Além disso, a busca nem sempre obtém sucesso devido às lacunas existentes principalmente no que se refere a conteúdos sobre temas locais, cuja abordagem é crítica e indispensável no ensino das Geociências.

O acesso à Internet permite a criação de um ambiente de aprendizagem cooperativo, e que permite fugir da chamada “educação bancária” de acumulação de conhecimento (Meira, 2002), em favor de situações nas quais os alunos podem explorar conteúdos, reter informações, elaborar questões, interagir com outros alunos e gerar conhecimento, até mesmo empregando os próprios recursos da Web (p. ex.: Projeto Globe, Butler e MacGregor, 2003). Ao invés de receber o conteúdo digerido, eles recebem a direção, orientação e inspiração do professor (Heide, 2000). O recurso dos hipertextos permite fugir da leitura linear; o acesso às informações é enriquecido com imagens, sons, vídeos e aplicativos que favorecem a criação de um ambiente agradável e dinâmico - e que, além disso, pode ser atualizado em tempo real, dependendo das necessidades e aplicações. Por outro lado, o uso do computador como ferramenta envolve custos (Kusnick, 2001), alguns óbvios, outros nem tanto. Dentre os custos intangíveis existe o perigo de desviar a atenção dos alunos do concreto para o mundo virtual, pois " $a$ interação dos estudantes com o computador deve ampliar seu entendimento e interesse pelo mundo natural, não diminuí-los” (Kusnick, 2001).

O conceito-chave quando se trata do uso de tecnologias de informação no meio educacional é “Aprender a Aprender”. Em outras palavras, o uso da Internet em sala-de-aula não deve ficar restrito a simples livros digitalizados, mas deve propiciar a conectividade do aluno com o universo de informações disponíveis e incentivar a aplicação dos conceitos sem se limitar ao espaço virtual.

\section{As Ciências da Terra no universo da Web}

Pacheco (1997) interpreta o hiperespaço como sendo um espaço público por excelência, caracterizado pela ausência de foco e de fronteiras. Cada computador tanto pode receber informações do mundo inteiro, como pode ainda enviá-las para quem quiser recebê-las. É esse universo de transmissão e recepção de dados que faz da Internet um recurso educacional que possui a capacidade de inovar as relações de ensino-aprendizagem. As disciplinas que compõem as Geociências não ficam fora do “turbilhão” de informações on-line que circulam pela grande rede. Diversas iniciativas têm surgido, seja para disponibilizar materiais didáticos e softwares para professores (Brilha e Legoinha, 1998; Medeiros Filho e Cintra, 1999; Otsuka, 1997), seja na forma de cursos (Rezende e Jesus, 1999; Rocha, 2002) ou excursões virtuais, ou ainda na forma de simples exposição de conteúdo educativo.

Entretanto, principalmente no contexto do idioma português, são raros os websites educacionais que oferecem um número significativo de ferramentas, proporcionando ao usuário os graus de atração e interação desejáveis. Há exemplos, como o GEOPOR na escola (www.geopor.pt/gne), uma iniciativa de docentes e do Ministério da Educação de Portugal que visa reunir e disponibilizar conteúdos relacionados às Geociências. No Brasil, há tentativas importantes de disponibilizar materiais para alunos que cursam o nível superior, sendo mais raros os websites que dirigem o foco ao ensino/aprendizagem de Geociências exclusivamente para os níveis fundamental e médio. É comum a mistura de informações variadas, situação em que a falta de um conteúdo organizado torna a navegação pouco atraente e de baixo grau de aproveitamento.

\section{ANÁLISE DE SITES}

\begin{abstract}
“É evidente a mais-valia da Internet para a actualização de conhecimentos dos docentes e, se bem utilizados os recursos, o trabalho de preparação de aulas fica extraordinariamente facilitado. Mais importante ainda, a utilização da Internet na sala-de-aula abre caminhos interessantes para melhor aprendizagem. A exploração de vários conteúdos geológicos na Internet em variadíssimos suportes (texto, hipertexto, imagem, animação, vídeo, som) permite o abandono do papel passivo dos alunos. Passando estes a assumir um papel de pesquisa, a definir o ritmo e percurso da sua aquisição de conhecimentos, o professor será gradualmente transformado num organizador das situações de aprendizagem, direcionando, validando e integrando o processo educativo" (Figueiredo, 2003, p. 1).
\end{abstract}

A análise sistemática de websites é importante por permitir o contato com o conteúdo didático em Geociências e proporcionar a criação de uma visão crítica sobre o desenvolvimento de websites educacionais. O processo de análise foi, necessariamente, antecedido pela criação de um método e pela definição de critérios de análise; um Banco de Dados foi construído especificamente para armazenamento das informações coletadas. O conteúdo pesquisado consiste basicamente de informações e materiais didáticos sobre diversos ramos das Geociências, que pudessem ser utilizados por professores de todos os níveis de ensino. $\mathrm{O}$ interesse despertado pelo produto da pesquisa evidenciouse em reuniões, fóruns de discussão e outros encontros de educadores deste campo da Ciência.

A análise de websites propicia uma visão crítica a respeito da acuidade visual, da qualidade do conteúdo informati- 
vo e da utilização de diferentes formas de exibição adotadas. Um bom website educacional requer a associação de ferramentas que estimulem a interatividade e curiosidade dos alunos, utilizando-se de gráficos, animações, jogos e hipertextos, além de permitir uma navegação fácil e agradável por esse universo on-line. Assim, o Banco Analítico de Dados deveria permitir, a educadores e alunos, um acesso fácil e rápido aos mais interessantes websites ligados às Geociências, enfatizando os recursos mais bem aproveitados em cada um deles.

\section{Abrangência e critérios}

O número de websites analisados ainda é pequeno, diante da abrangência propiciada pela Internet. Na primeira etapa do projeto vislumbrou-se, de modo mais aprofundado, o potencial de influência da Internet em atividades educacionais, em particular no funcionamento como ferramenta e uma nova estratégia para o Ensino das Ciências da Terra. Basta digitar "geology" como palavra-chave em um programa de busca que surgem mais de quatro milhões de links. Decidiu-se privilegiar, portanto, os endereços mais completos de caráter educacional, as fontes de informações para outros websites, e sítios que fossem constantemente citados na forma de links de referência.

A análise contemplou 91 websites, um número significativo, considerando-se que para cada um deles foi feita uma descrição detalhada. Ao preencher a tabela de classificação, todos os endereços foram revisitados várias vezes, com a intenção de verificar o grau de atualização. O produto final da análise, ou seja, o banco analítico de dados totalmente preenchido, possibilita extrair algumas conclusões a respeito do universo de websites visitados. Dos 91 espaços virtuais analisados, a maioria (54) oferece conteúdo em português (Figura 1). Esse fator é decisivo, na medida em que aumenta o acesso de professores e alunos menos familiarizados com línguas estrangeiras. Entretanto, não é possível ignorar os websites em inglês, muito mais numerosos, e que, provavelmente, reúnem o mais amplo acervo de informações. São websites que também contam com excelente conteúdo pedagógico.

Destaca-se ainda, na seção de "Temas Cobertos em Geociências”, a predominância de conteúdo pouco específico e de caráter mais abrangente, como é o caso de Geologia Geral. Esse é um fator positivo se considerarmos a utilização dos websites para disciplinas do ensino fundamental e médio, nas quais deve ser privilegiada a abordagem de temas gerais sobre o funcionamento do Sistema Terra. No critério “Tipo de Material Disponível”, nota-se que boa parte dos websites conta com ilustrações, mas é baixa a oferta de recursos como animações e aplicativos (Figura 2), importantes para promover a interação do aprendiz com o conteúdo

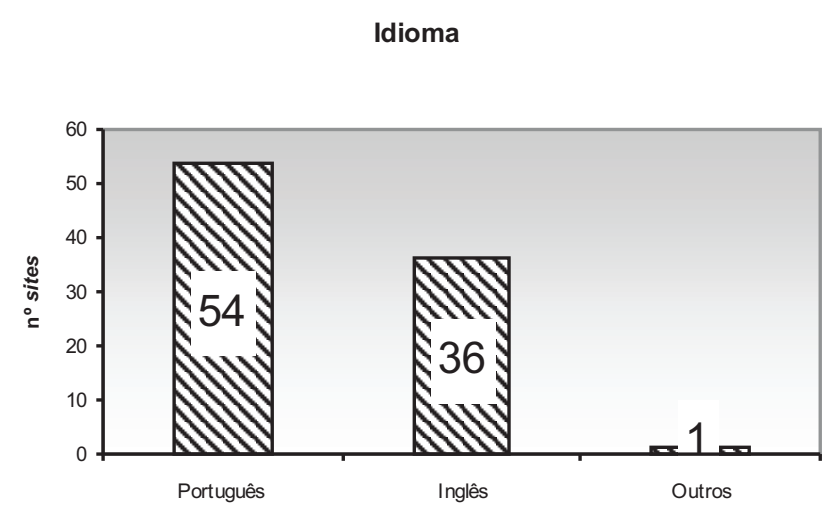

Figura 1. Idioma em que se apresentam os websites analisados.

trabalhado. Outro recurso que facilita o aprendizado por meio da interação com o usuário é a utilização de hipermapas, ou seja, mapas interativos onde o usuário seleciona as informações que deseja ver representadas. Com algumas exceções, a maioria dos mapas disponibilizados consiste em simples cópias de mapas convencionais.

\section{Criação de Banco de Dados}

A análise, organização e classificação de websites relacionados às Geociências parte da premissa de que as informações encontram-se dispersas na rede mundial de computadores e isentas de qualquer mensuração; o resultado dessa situação é um uso muito conservador e restrito nos meios educacionais. $\mathrm{O}$ instrumento de pesquisa, que foi iniciado por outro bolsista em etapa anterior do projeto (Machado, 2002), consiste de um formulário de coleta de informações e uma planilha em Microsoft Excel, cujos campos foram aperfeiçoados na fase final do projeto, de acordo com as necessidades encontradas na análise preliminar de 50 websites.

$\mathrm{O}$ atual modelo de Banco de Dados, aperfeiçoado, manteve o objetivo de avaliar a qualidade das informações fornecidas na Internet, o tipo de material disponível, a navegabilidade e a proposta de indicar a faixa escolar para a qual é mais indicado o sítio analisado. Os campos estão discriminados abaixo:

1. Número: utilizado como simples codificação dos endereços já visitados.

2. Título: referente ao nome dado pelo próprio autor que criou o website. Serve numa primeira análise para orientação conforme o assunto desejado.

3. Endereço: contém o endereço de acesso ao conteúdo analisado. Trata-se de um hiperlink, no qual, clicando com 
Tipo de Material Disponível

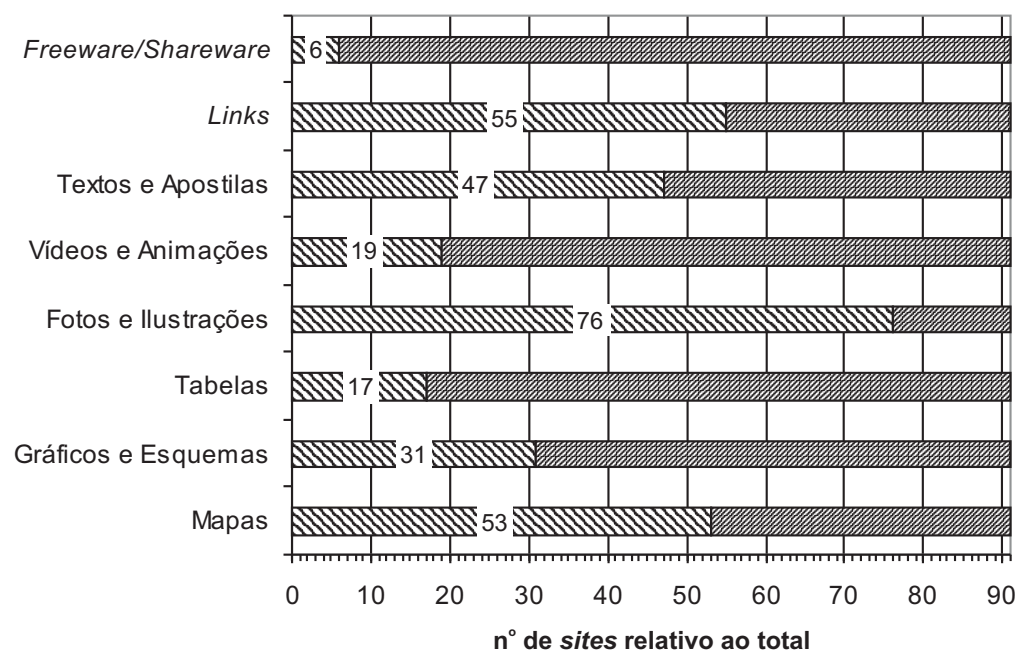

Figura 2. Características gerais dos materiais disponíveis nos websites analisados.

o cursor do mouse sobre o texto, automaticamente iniciarse-á o software de navegação com o website selecionado.

4. Idioma: contém o idioma no qual se encontram as informações. No caso de um website com versões em vários idiomas, aborda-se preferencialmente o português ou, caso este não conste na lista, considera-se o inglês, que é o idioma de maior abrangência.

5. Data da última visita: campo utilizado como referência para eventuais visitas futuras a um mesmo website.

Os campos descritos acima servem basicamente como identificação do website a ser analisado. São informações colhidas à primeira vista. Os campos descritos a seguir contêm informações relevantes à utilização do website para fins educacionais, abordando tópicos sobre a navegabilidade e facilidade de acesso ou ainda especificamente sobre o conteúdo de informações e materiais didáticos:

1. Navegabilidade: procura englobar de forma simplificada, em um único campo, fatores como a facilidade de acesso, a clareza na estrutura, na aparência e no design. Esses cuidados na elaboração de um website são essenciais para evitar um número exagerado de hiperlinks, ou arquivos demasiadamente grandes que demorem a ser carregados. Deve-se ainda procurar manter um visual consistente e uniforme que valorize a organização das informações e evite a sobrecarga da tela. A navegabilidade está classificada entre quatro opções selecionadas a partir de uma caixa de seleções no Banco de Dados, são elas: Ruim, Regular, Boa e Excelente.

2. Categoria institucional: refere-se ao responsável pelas informações contidas no website. Divide-se em categoria Pessoal, Universidade Pública, Universidade Privada, Órgão de Pesquisa Público, Órgão de Pesquisa Privado, Organização não-Governamental, Empresa Pública, Empresa Privada e uma "Categoria Indefinida” para os websites que não se encaixarem nas opções acima. Este é um campo importante, pois pode refletir parte da confiabilidade do material disponível.

3. Faixa escolar indicada: consiste em quatro caixas de seleção (Ensino Fundamental, Ensino Médio, Ensino Superior e Indefinido), as quais podem ser preenchidas independentemente umas das outras, ou simultaneamente. Há websites voltados exclusivamente para uma faixa de ensino, já outros possuem conteúdo mais abrangente e envolvem conceitos para mais de um nível. Esse campo interessa aos educadores, que poderão buscar materiais para determinado nível de ensino em que atuam, reduzindo o tempo gasto com buscas na rede.

4. Nível de abordagem: também se refere ao nível das informações abordadas pelo website, porém divide-se em três categorias: nível técnico, científico e educacional. Assim, 
distingue-se a forma como as informações são abordadas. O nível técnico traz mais detalhes para profissionais atuantes na área de Geociências, o científico traz publicações e trabalhos acadêmicos, informações sobre pesquisa nas universidades e institutos etc. Já o nível educacional é talvez o que mais interessou à pesquisa, ao dispor didaticamente as informações e concentrar-se no aspecto educativo.

5. Temas cobertos em Geociências: este item consiste de um conjunto de temas considerados relevantes no ensino de Geociências. Não se trata de temas muito específicos, mas categorias abrangentes, as quais formam um universo bem completo sobre o assunto. Dificilmente um mesmo website abordará todos os temas (Figura 3), por isso as alternativas que podem ser indicadas por meio das caixas de seleção são independentes e aparecem marcadas nos itens em que existir uma referência ao assunto dentro do conteúdo analisado.
6. Tipo de material disponível: são caixas de seleção preenchidas de acordo com as formas de disponibilidade do conteúdo do website, que pode ser feito por meio de Mapas, Gráficos e Esquemas, Tabelas, Fotos e Ilustrações, Vídeos e Animações, Textos e Apostilas, Aplicativos, Links, dentre outros. Este é um campo importante, pois reflete a forma como o website utiliza os recursos oferecidos pela Internet. Uma abordagem do conteúdo de forma puramente textual não passa de um "livro digitalizado", assim, o interessante é a riqueza de informações auxiliada pelas múltiplas linguagens expositivas disponíveis.

7. Apreciação: contém uma síntese relativa à análise do website. É um campo “conclusivo” do Banco de Dados, pois procura tratar criticamente aspectos de conteúdo e navegabilidade, realçar as inovações, indicar seções de maior interesse aos professores e alunos e, finalmente, indicar categorias e temas mais específicos.

\section{Temas Cobertos em Geociências}

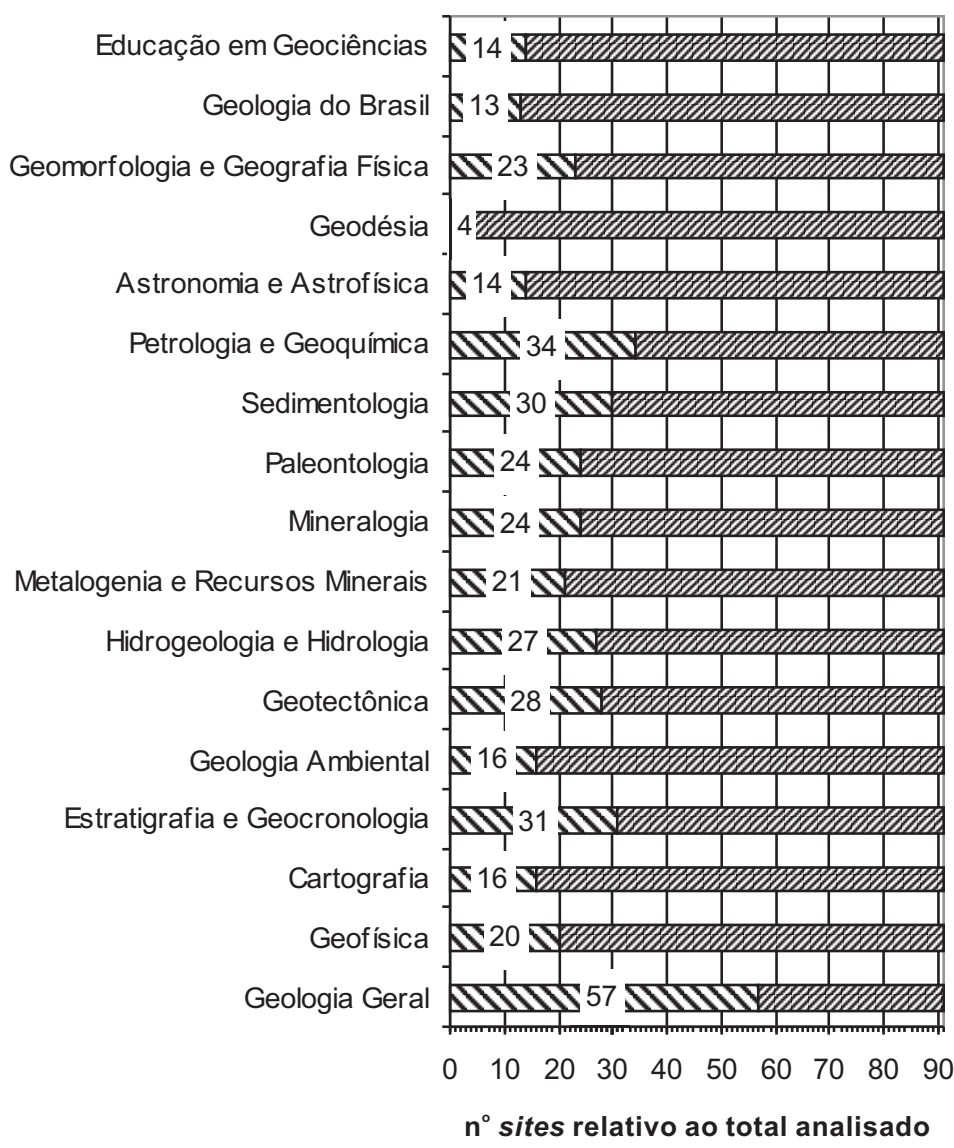

Figura 3. Distribuição quantitativa dos temas de Geociências recobertos pelos websites. 


\section{Seleção de temas}

Na seleção de “Temas Cobertos em Geociências” procurou-se enfatizar assuntos relevantes para ensino de Geociências na Educação Básica. A análise deveria valorizar os conteúdos desenvolvidos de modo mais completo, independentemente da quantidade de temas recobertos. Os temas analisados foram: Geologia Geral, Cartografia, Estratigrafia e Sedimentologia, Geologia Ambiental, Geotectônica, Hidrologia e Hidrogeologia, Metalogênese e Recursos Minerais, Mineralogia, Paleontologia, Geologia Regional e Geologia do Brasil, Petrologia, Petrografia e Geoquímica, Geofísica, Geomorfologia e Geografia Física, Astronomia e Astrofísica, Educação em Geociências.

A pesquisa investigou ainda o problema do conteúdo regional. Um levantamento acerca de temas de maior interesse para serem tratados com o auxílio da Informática, junto a professores de Ciências e Geografia da região de Jundiaí e Atibaia (SP) (Carneiro e Barbosa, 2002a, 2002b), identificou forte demanda por temas de natureza regional, ao lado de alguns mais teóricos, como: água, ciclo hidrológico e ciclos da natureza. Os temas regionais mais solicitados foram: riscos naturais, trabalhos de campo (estudos do meio) na região e Geologia Regional.

\section{Classificação dos Websites}

A idéia de classificar os diferentes websites surgiu da preocupação de distinguir os melhores e mais completos espaços de disseminação de conteúdo educativo na rede mundial de computadores. Com um produto desses em mãos, professores e alunos, que muitas vezes se perdem em meio ao universo digital, têm a possibilidade de selecioná-los e consultar materiais on-line de boa qualidade. A atribuição de conceitos que variam de 0 a 4 (Quadro 1) - possibilita caracterizar um website de acordo com diversos critérios estabelecidos com base em consultas bibliográficas e no exame do material coletado.

Quadro 1. Conceitos atribuídos às características de websites educacionais.

\begin{tabular}{|c|c|}
\hline Nota & Conceito \\
\hline 0 & Muito Ruim/Ausente \\
1 & Ruim \\
2 & Regular \\
3 & Bom \\
4 & Excelente \\
\hline
\end{tabular}

Há grande número de trabalhos na literatura que estabelecem critérios de avaliação ou desenvolvimento de softwares educacionais (p. ex.: Gallaguer, 2000a, 2000b, 2000c), porém no que se refere a websites tais pesquisas começam a se tornar mais freqüentes (p. ex.: Gore, 1997; Huntoon e Ridky, 2002). Apesar da semelhança que ambos possam ter, principalmente em relação a softwares do tipo tutorial, algumas características substanciais os diferem. Segundo Valente (1999), o software multimídia está cada vez mais atrativo e interessante, com aplicações de conteúdo cada vez mais bem elaboradas; entretanto, o usuário está sempre restrito aos recursos disponíveis. Se um determinado software não possui o que o usuário deseja, o mesmo deve partir para a busca ou aquisição de outro. Em relação à Internet, esse problema não ocorre, pois, a custos muito baixos, o usuário tem disponível um acervo de informações praticamente ilimitado.

Entretanto, tal abrangência reflete-se em dificuldade do usuário na localização do conteúdo desejado, além do mesmo estar sujeito a grande perda de tempo, principalmente, risco de se desvirtuar o caráter inicial da pesquisa. Como conseqüência, tem-se o baixo aproveitamento dos abundantes recursos disponíveis pela grande rede, fato que atrapalha a aplicação educacional desses recursos.

"No processo de navegar, o aprendiz pode entrar em contato com um número incrível de idéias diferentes. Mas se esta informação não é posta em uso, não há nenhuma maneira de estarmos seguros de que esta informação será transformada em conhecimento" (Valente, 1999, p. 100).

Assim, procurou-se estabelecer, dentro de um universo de websites analisados (Quadro Analítico), diversos critérios que possibilitem a atribuição de conceitos de ordem numérica para destacar aqueles mais completos e que façam melhor uso dos recursos disponíveis. Embora a classificação e a pontuação decorrente possam ser até certo ponto subjetivas, é importante ressaltar os critérios empregados, para permitir a eventual replicação da análise:

1. Navegabilidade: o website deve permitir um rápido contato com as informações, proporcionar uma navegação intuitiva e com comandos diretos, caracterizando, assim, um espaço organizado e facilmente acessível.

2. Aparência e design: referem-se à característica de proporcionar navegação agradável sem uma carga visual pesada de cores gritantes, além da presença de páginas padronizadas etc.

3. Qualidade das informações: um bom website deve possuir conteúdo teórico confiável, utilizando diferentes ferramentas disponíveis em meio digital, sem perder as qualidades de um bom livro. Deve ser claro na exposição dos 
temas, trazer figuras e animações de boa qualidade visual e conceitual. Além disso, a seleção das informações disponibilizadas é muito importante: é preferível um website com pequeno número de assuntos, mas abordados de maneira completa, do que a superficialidade em grande variedade de temas. É essencial ainda a apresentação das fontes bibliográficas, as quais atribuem confiabilidade ao material exposto.

4. Abrangência de temas: relaciona-se às diversas áreas das Geociências, representadas por um ou mais temas, dentre aqueles definidos acima. Este item não influencia muito na classificação, pois, como se enfatizou no item anterior, a qualidade da informação supera a variedade.

5. Uso de recursos multimídia: a principal vantagem do meio digital em relação aos meios tradicionais de disponibilidade de informações é a de possibilitar o uso de ferramentas que tornem a atividade mais agradável e o conteúdo mais facilmente absorvido. $\mathrm{O}$ uso equilibrado de recursos como fotos e gráficos, vídeos, animações e aplicativos enriquecem o conteúdo teórico e aproxima o aprendiz do assunto abordado. Além disso, o hipertexto possibilita uma navegação não linear pela teoria e fornece ao usuário o controle sobre o avanço da leitura ou pesquisa em temas paralelos.

6. Grau de inovação: refere-se à utilização de recursos pouco aproveitados pela maioria dos websites, mas que, se bem aplicados, podem proporcionar resultados interessantes. Além de ser fácil reconhecer um website inovador, a navegação torna-se mais interessante devido à curiosidade na exploração de todo o conteúdo.

7. Variedade de links: outro recurso interessante de websites é a indicação de outros endereços que possam servir de complemento às informações apresentadas. Pode-se ainda explorar links para revistas e periódicos especializados ou órgãos de pesquisa.

8. Auto-suficiência: parte da qualidade de um website deve-se à sua independência de dados sobre determinados assuntos sem serem necessárias visitas a outros websites, que muitas vezes, podem ser feitas por meio de ligações no próprio menu que levam à abertura de uma nova página. Um website com baixa auto-suficiência pode tornar a navegação repetitiva, pois o usuário, na busca por determinado assunto, provavelmente visitará a página que serviu de link e ali permanecer; assim, o website não acrescentará qualquer informação ou recursos novos.

9. Conteúdo regional: uma das principais deficiências no uso da Internet para o ensino de Geociências é a limitada abordagem de conteúdos regionais. Por conteúdo regional entende-se as informações que tratam de regiões ou áreas geográficas mais próximas ao aprendiz, tratadas de modo a facilitar a compreensão. Assim, estabeleceu-se como critério a abordagem e a forma de tratamento dessas informações regionais sobre o meio natural.
10. Aplicação pedagógica em Geociências: este trabalho trata da análise de websites em Geociências, procurando destacar a aplicabilidade desse recurso no ensino e evidenciar as principais características que trazem eficiência e facilitam o aprendizado. Portanto, um campo essencial da classificação engloba a abordagem de temas de interesse de professores do ensino fundamental e médio. Além desses níveis de ensino, procurou-se enfatizar ainda a utilização do website em disciplinas do ensino superior e a utilização de recursos que auxiliam os educadores, sugerindo atividades e temas para discussão.

11. Ponderação das notas: é o campo que finaliza a classificação e pondera o peso dos diferentes critérios. Os pesos foram atribuídos de acordo com a relevância de cada critério para a obtenção do objetivo, ou seja, de acordo com a importância em tornar o website uma fonte de disseminação de informações ligadas às Geociências. O resultado final é expresso em notas que variam de 0 a 10 e estas foram calculadas na própria planilha, mediante ponderação dos campos. O procedimento foi o de recalcular as antigas notas de 0 a 4 e, baseando-se na somatória de pontos, chegar à classificação final. Com isso é possível visualizar o ranking dos websites que mais pontos obtiveram e que possam servir de exemplo para o desenvolvimento de outros.

Em cada um desses critérios, destacaram-se as características desejáveis a um bom website educacional (Tabela 1). A presença ou não dessas características serve de parâmetro que permite atribuir conceitos de 0 a 4 (conforme a Tabela 2), ou seja, dependendo do número de características positivas presentes, o website se encaixa em uma classe de 0 a 4 para cada critério estabelecido.

A etapa final do processo de classificação de websites é organizar a tabela preenchida, que contém todas as notas atribuídas, de forma a expressar uma ordem decrescente na coluna "Ponderação de notas". Assim, tem-se como resultado o ranking, onde os primeiros websites são, de acordo com os critérios estabelecidos, os mais completos e que possuem um grande leque de aplicações pedagógicas em Geociências.

O produto gerado nesse trabalho revela-se um interessante acervo de fontes de informações virtuais. Todos os websites da lista, além de estar ordenados de acordo com os critérios estabelecidos, foram analisados e acham-se dispostos em Banco de Dados, que dá acesso aos detalhes e às características de cada um. Assim, educadores e alunos dispõem de recursos on-line originais, de alta qualidade e facilmente localizáveis utilizando o ranking e o Banco de Dados como guia de navegação. Além disso, diversos websites podem servir de modelo para a criação de outros espaços virtuais de uso educacional em Geociências. 
Tabela 1. Listagem de critérios e características positivas em um website.

\begin{tabular}{|c|c|}
\hline Critério & Características positivas \\
\hline $\begin{array}{l}\text { Navegabilidade } \\
\text { (Peso 2) }\end{array}$ & $\begin{array}{l}\text { Páginas leves e de rápido acesso } \\
\text { Endereço facilmente memorizável e ligado ao tema do website } \\
\text { Menu Principal bem estruturado } \\
\text { Links de navegação ("voltar à página anterior", "voltar ao menu principal" etc.) } \\
\text { Links centralizados seguindo o menu principal e valorizando o aspecto intuitivo de navegação. Evita links dispersos que "ocultam" informações } \\
\text { Uso de hotwords para identificar links no texto } \\
\text { Ausência de abertura de páginas sem solicitação do usuário } \\
\text { Mapa do conteúdo do website } \\
\text { Ausência de links que não funcionem, o que evita a frustração do usuário }\end{array}$ \\
\hline $\begin{array}{l}\text { Design } \\
\text { (Peso 2) }\end{array}$ & $\begin{array}{l}\text { Equilíbrio do uso de imagens, sons, textos e animações } \\
\text { Páginas não muito longas } \\
\text { Páginas leves visualmente, sem cores gritantes nem luminosos que irritam após um determinado período de navegação } \\
\text { Uso de fontes adequadas e de fácil visualização } \\
\text { Aspecto padronizado para as diversas páginas pertencentes ao website } \\
\text { Uso de ferramentas intuitivas, por exemplo, o uso de cores de fundo associadas a temas abordados } \\
\text { Uso de imagens de boa definição e tamanho }\end{array}$ \\
\hline $\begin{array}{l}\text { Qualidade das } \\
\text { informações } \\
\text { (Peso 3) }\end{array}$ & $\begin{array}{l}\text { Conteúdo bem selecionado e coerente com o tema proposto } \\
\text { Redação e textos bem elaborados e livres de erros gramaticais } \\
\text { Informações fundamentadas e/ou originadas de fontes oficiais } \\
\text { Evita a simplificação excessiva, perdendo a qualidade do texto } \\
\text { Uso de exemplos para os temas tratados e/ou uso de ilustrações explicativas } \\
\text { Constante atualização dos assuntos abordados }\end{array}$ \\
\hline $\begin{array}{l}\text { Abrangência de } \\
\text { temas } \\
\text { (Peso 1) }\end{array}$ & $\begin{array}{l}\text { Geologia Geral } \\
\text { Cartografia } \\
\text { Estratigrafia e Sedimentologia } \\
\text { Geologia Ambiental } \\
\text { Geotectônica } \\
\text { Hidrologia e Hidrogeologia } \\
\text { Metalogênese e Recursos Minerais } \\
\text { Mineralogia } \\
\text { Paleontologia } \\
\text { Geologia Regional e Geologia do Brasil } \\
\text { Petrologia, Petrografia e Geoquímica } \\
\text { Geofísica } \\
\text { Geomorfologia e Geografia Física } \\
\text { Astronomia e Astrofísica } \\
\text { Educação em Geociências }\end{array}$ \\
\hline $\begin{array}{l}\text { Uso de recursos } \\
\text { multimídia } \\
\text { (Peso 2) }\end{array}$ & $\begin{array}{l}\text { Evita a simples transposição de um livro para o computador, utiliza ferramentas não-lineares de texto } \\
\text { Disponibilidade de mapas interativos que possibilitem ao usuário optar pelas informações a serem representadas ("Hipermapas" ou "mapas clicáveis") } \\
\text { Mapas simples digitalizados ou escanerizados } \\
\text { Uso de recursos do tipo "Trabalhos de Campo Virtuais" } \\
\text { Vídeos e animações } \\
\text { Softwares e aplicativos } \\
\text { Imagens e fotos ilustrativas }\end{array}$ \\
\hline $\begin{array}{l}\text { Grau de inovação } \\
\text { (Peso 1) }\end{array}$ & $\begin{array}{l}\text { Uso de recursos multimídia raramente utilizados (presentes em menos de } 5 \% \text { dos websites analisados) } \\
\text { Abordagem de temas raramente utilizados (presentes em menos de } 5 \% \text { dos websites analisados) } \\
\text { Abordagem de temas inusitados, porém de interesse educativo (situações cotidianas, por exemplo) } \\
\text { Aplicativos desenvolvidos exclusivamente } \\
\text { Fonte de informações para outros websites }\end{array}$ \\
\hline $\begin{array}{l}\text { Variedade de } \\
\text { links } \\
\text { (Peso 2) }\end{array}$ & $\begin{array}{l}\text { Links para outros websites que complementem as informações a respeito do mesmo assunto principal visto durante a navegação } \\
\text { Links para websites que abordem temas diferentes do assunto ao longo da visita } \\
\text { Links para websites de outras Ciências como Física, Química, Biologia etc. } \\
\text { Links para revistas e periódicos científicos } \\
\text { Resumo dos principais assuntos e características de cada link ou grupo de links } \\
\text { Links para fontes de informações oficiais (órgãos do governo, universidades e institutos de pesquisa) }\end{array}$ \\
\hline $\begin{array}{l}\text { Auto-suficiência } \\
\text { (Peso 3) }\end{array}$ & $\begin{array}{l}\text { Textos redigidos especialmente para o website } \\
\text { Ausência de temas abordados exclusivamente por meio de links para outros sites especializados } \\
\text { Imagens, animações e aplicativos exclusivos } \\
\text { Websites associados a universidades ou órgãos de pesquisas que produzem todo o conteúdo e funciona como fonte de informações para outros sites }\end{array}$ \\
\hline $\begin{array}{l}\text { Conteúdo } \\
\text { regional } \\
\text { (Peso 2) }\end{array}$ & $\begin{array}{l}\text { Mapas em escalas regionais } \\
\text { Dados sobre geologia e geomorfologia regional } \\
\text { Sugestões de atividades de campo a curtas distâncias } \\
\text { Apresentação ilustrada das principais características naturais encontradas } \\
\text { Inserção das características regionais em escala global e/ou associação com temas mais abrangentes }\end{array}$ \\
\hline $\begin{array}{l}\text { Aplicação } \\
\text { pedagógica } \\
\text { em Geociências } \\
\text { (Peso 4) }\end{array}$ & $\begin{array}{l}\text { Abordagem de temas pertinentes ao ensino médio e básico } \\
\text { - Água e ciclo hidrológico / ciclos da natureza / riscos naturais } \\
\text { - Formação do universo / esferas terrestres / meteorologia, clima e energia; } \\
\text { - Tempo geológico / rochas e minerais / geomorfologia } \\
\text { Abordagens de temas pertinentes ao ensino superior } \\
\text { Informações de caráter regional } \\
\text { Sugestões de atividades (trabalhos de campo, experimentos e outros) }\end{array}$ \\
\hline
\end{tabular}


Tabela 2. Padrão para atribuição de conceitos aos websites.

\begin{tabular}{lccccc}
\hline \multirow{2}{*}{ Critério } & \multicolumn{4}{c}{$\mathbf{N}^{\circ}$ de características positivas } & (listadas na Tabela 1) \\
\cline { 2 - 6 } & Conceito 0 & Conceito 1 & Conceito 2 & Conceito 3 & Conceito 4 \\
\hline Navegabilidade & Nenhuma & 1 a 3 & 4 a 6 & 6 a 8 & Todas (9) \\
Design & Nenhuma & 1 a 2 & 3 a 4 & 5 a 6 & Todas (7) \\
Qualidade das informações & Nenhuma & 1 & 2 a 3 & 4 a 5 & Todas (6) \\
Abrangência de temas & Nenhuma & 1 a 3 & 4 a 6 & 7 a 9 & 10 a 15 \\
Uso de recursos multimídia & Nenhuma & 1 a 2 & 3 a 4 & 5 a 6 & Todas (7) \\
Grau de inovação & Nenhuma & 1 & 2 & 3 & 4 a 5 \\
Variedade de links & Nenhuma & 1 & 2 & 3 a 4 & 5 a 6 \\
Auto-suficiência & Nenhuma & 1 & 2 & 3 & Todas (4) \\
Conteúdo regional & Nenhuma & 1 & 2 & 3 & 4 a 5 \\
Aplicação pedagógica em Geociências & Nenhuma & 1 & 2 & 3 & Todas (4) \\
\hline
\end{tabular}

\section{QUADRO ANALÍTICO}

Quadro sintético da listagem e pontuação dos 91 websites analisados. (*) 1. Navegabilidade. 2. Design. 3. Qualidade das informações. 4. Abrangência de temas. 5. Uso de multimídia. 6. Grau de inovação. 7. Variedade de links. 8. Autosuficiência. 9. Conteúdo regional. 10. Aplicação pedagógica em Geociências. (**) Ponderação de notas (0 a 10).

\begin{tabular}{|c|c|c|c|c|c|c|c|c|c|c|c|c|c|}
\hline \multirow{2}{*}{$\mathrm{N}^{\circ}$} & \multirow{2}{*}{ Titulo } & \multirow{2}{*}{ Website } & \multicolumn{10}{|c|}{ Critérios (*) } & \multirow{2}{*}{$(* *)$} \\
\hline & & & 1 & 2 & 3 & 4 & 5 & 6 & 7 & 8 & 9 & 10 & \\
\hline 1 & GEOPOR na Escola & http://www.geopor.pt/gne/index.html & 3 & 4 & 4 & 4 & 3 & 3 & 2 & 4 & 4 & 4 & 9,0 \\
\hline 2 & U. S. Geological Survey & http://www.usgs.govl & 3 & 4 & 4 & 4 & 3 & 2 & 2 & 4 & 4 & 4 & 8,9 \\
\hline 3 & British Geological Survey - Education & http://www.bgs.ac.uk/education/home.html & 3 & 4 & 4 & 2 & 3 & 2 & 3 & 4 & 4 & 4 & 8,9 \\
\hline 4 & Subsídios para Elaboração e Implantação da Agenda 21 & http://www.cnpm.embrapa.br/projetos/agenda21/index.html & 4 & 4 & 4 & 2 & 3 & 4 & 2 & 4 & 4 & 3 & 8,6 \\
\hline 5 & USGS Learning Web & http://www.usgs.gov/education/ & 3 & 4 & 3 & 3 & 3 & 2 & 3 & 4 & 3 & 4 & 8,4 \\
\hline 6 & CPRM - Serviço Geológico do Brasil & http://www.cprm.gov.br/ & 2 & 3 & 4 & 4 & 4 & 1 & 3 & 4 & 4 & 3 & 8,3 \\
\hline 7 & Instituto Geológico e Mineiro - Portugal & http://www.igm.pt/ & 3 & 3 & 4 & 4 & 2 & 2 & 3 & 4 & 4 & 3 & 8,2 \\
\hline 8 & BBC Education - The essential guided to rocks & http://www.bbc.co.uk/education/rocks & 3 & 3 & 3 & 2 & 3 & 2 & 2 & 4 & 4 & 4 & 8,1 \\
\hline 9 & MINEROPAR - Minerais do Paraná AS & http://www.pr.gov.br/mineropar/ & 3 & 3 & 4 & 2 & 2 & 2 & 1 & 4 & 4 & 3 & 7,5 \\
\hline 10 & Cepagri - Meteorologia - Unicamp & http://www.cpa.unicamp.br/ & 3 & 4 & 4 & 1 & 2 & 2 & 2 & 4 & 2 & 3 & 7,4 \\
\hline 11 & Sítios Geológicos e Paleontológicos do Brasil & http://www.unb.br/ig/sigep/sitios.htm & 2 & 3 & 4 & 3 & 2 & 2 & 0 & 4 & 4 & 3 & 7,2 \\
\hline 12 & Centro de Previsão do Tempo e Estudos Climáticos & http://www.cptec.inpe.br/ & 4 & 3 & 4 & 2 & 2 & 3 & 3 & 4 & 1 & 2 & 7,2 \\
\hline 13 & Sociedade Brasileira de Geologia & http://sbg.igc.usp.brl & 3 & 2 & 3 & 1 & 2 & 1 & 2 & 3 & 4 & 4 & 7,0 \\
\hline 14 & Big Bend National Park - Texas A\&M University & http://www.maroon.com/bigbend/ & 4 & 3 & 4 & 3 & 2 & 2 & 1 & 4 & 4 & 1 & 6,9 \\
\hline 15 & Fossil.uc.pt & http://fossil.uc.pt/ & 2 & 4 & 3 & 1 & 3 & 2 & 0 & 3 & 3 & 3 & 6,5 \\
\hline 16 & PROCLIMA - Progr. de Monit. Climático em Tempo Real & http://www.cptec.inpe.br/proclima/ & 3 & 3 & 4 & 1 & 2 & 2 & 2 & 4 & 1 & 2 & 6,5 \\
\hline 17 & GEO-DATA Explorer - USGS & http://geode.usgs.gov/ & 3 & 4 & 4 & 2 & 2 & 2 & 2 & 4 & 1 & 1 & 6,4 \\
\hline 18 & Rock Cycle - Rochas Ígneas & http://gly1000-01.su00.fsu.edu/ig/ & 2 & 3 & 3 & 2 & 2 & 3 & 2 & 4 & 0 & 3 & 6,4 \\
\hline 19 & Serra do Japi & http://www.japi.org.br & 2 & 3 & 3 & 1 & 3 & 2 & 0 & 2 & 4 & 3 & 6,1 \\
\hline 20 & GEOPOR - Ciências da Terra na Internet & http://www.geopor.pt/index.html & 2 & 3 & 3 & 4 & 2 & 2 & 2 & 3 & 2 & 2 & 6,1 \\
\hline 21 & Associação Brasileira de Águas Subterrâneas & http:///www.abas.org.br/ & 2 & 3 & 4 & 1 & 2 & 1 & 3 & 4 & 2 & 1 & 6,1 \\
\hline 22 & Glacier & http://www.glacier.rice.edul & 3 & 4 & 4 & 1 & 2 & 1 & 0 & 4 & 1 & 2 & 6,1 \\
\hline 23 & Geology Labs - On Line & http://www.sciencecourseware.com $/$ & 2 & 3 & 3 & 2 & 3 & 3 & 0 & 4 & 0 & 3 & 6,1 \\
\hline 24 & About Geology & http://geology.about.com/ & 2 & 2 & 4 & 4 & 1 & 2 & 4 & 2 & 0 & 3 & 6,1 \\
\hline 25 & Astronomia e Astrofisica & http://astro.if.ufrgs.br/ & 4 & 3 & 4 & 1 & 3 & 2 & 1 & 3 & 0 & 2 & 6,1 \\
\hline 26 & Meio Ambiente pro Br & http://www.meioambiente.pro.br/index.htm & 3 & 2 & 3 & 2 & 2 & 1 & 0 & 3 & 3 & 3 & 6,0 \\
\hline 27 & Vulcano Word & http://volcano.und.nodak.edul & 2 & 2 & 3 & 2 & 2 & 1 & 2 & 3 & 2 & 3 & 6,0 \\
\hline 28 & Geomorphology from Space & http://daac.gsfc.nasa.gov/DAAC DOCS/geomorphology/GEO HOME PAGE.html & 3 & 3 & 4 & 2 & 3 & 1 & 1 & 4 & 1 & 1 & 6,0 \\
\hline 29 & Siccar Point Preview & http://www.glg.ed.ac.uk/courses/field/siccarpt/ & 3 & 3 & 3 & 2 & 1 & 0 & 2 & 3 & 3 & 2 & 5,9 \\
\hline 30 & About Earthquakes & http://www.seismo.unr.edu/htdocs/abouteq.html & 2 & 2 & 3 & 2 & 1 & 0 & 1 & 3 & 2 & 4 & 5,9 \\
\hline 31 & Instituto de Geociências - UnB & http://www.unb.br/ig/ & 2 & 2 & 3 & 4 & 1 & 1 & 2 & 4 & 2 & 2 & 5,9 \\
\hline 32 & Programa de Monitoramento de Queimadas - CPTEC & http://www.cptec.inpe.br/products/queimadas/ & 3 & 3 & 3 & 1 & 2 & 2 & 3 & 4 & 1 & 1 & 5,9 \\
\hline 33 & IBGE - Geociências & http://www.ibge.gov.br/ & 3 & 3 & 4 & 2 & 2 & 0 & 3 & 4 & 0 & 1 & 5,9 \\
\hline 34 & Enciclopédia - Instituto de Geociências - USP & http://www.igc.usp.br/Geologial & 2 & 3 & 3 & 4 & 1 & 1 & 3 & 3 & 1 & 2 & 5,8 \\
\hline 35 & Geoestatistica on-line & http://www.igc.usp.br/subsites/geoestatistical & 4 & 4 & 4 & 1 & 1 & 2 & 1 & 4 & 0 & 1 & 5,8 \\
\hline 36 & Projeto Jundiati & $\underline{\text { http: } / / \text { www.ige.unicamp.br/ -iundiati/ }}$ & 2 & 2 & 3 & 2 & 1 & 1 & 1 & 4 & 3 & 2 & 5,7 \\
\hline 37 & Geology - Earth's Interior & http://www.earth.nwu.edu/people/seth/B02/ & 3 & 3 & 4 & 3 & 1 & 1 & 3 & 2 & 0 & 2 & 5,7 \\
\hline 38 & Stratigraphy and Sedimentology on Colorado Plateu & http://jan.ucc.nau.edu/ rcb7l & 2 & 2 & 3 & 1 & 2 & 0 & 2 & 3 & 3 & 2 & 5,6 \\
\hline 39 & Geologia e Recursos Minerais & http://planeta.terra.com.br/educacao/br recursosminerais/ & 1 & 1 & 3 & 4 & 3 & 1 & 3 & 1 & 2 & 3 & 5,6 \\
\hline 40 & Embrapa - Brasil Visto do Espaço & http://www.cdbrasil.cnpm.embrapa.br/ & 3 & 4 & 4 & 1 & 2 & 2 & 0 & 4 & 0 & 1 & 5,6 \\
\hline
\end{tabular}


(Quadro Analítico - continuação)

\begin{tabular}{|c|c|c|c|c|c|c|c|c|c|c|c|c|c|}
\hline \multirow{2}{*}{$\mathbf{N}^{\circ}$} & \multirow{2}{*}{ Titulo } & \multirow{2}{*}{ Website } & \multicolumn{10}{|c|}{ Critérios $\left(^{*}\right)$} & \multirow{2}{*}{$(* *)$} \\
\hline & & & 1 & 2 & 3 & 4 & 5 & 6 & 7 & 8 & 9 & 10 & \\
\hline 41 & Georgia Geoscience OnLine - Physical Geology & http://gpc.edu/ pgore/online/physical2.php & 3 & 3 & 3 & 3 & 1 & 0 & 3 & 3 & 0 & 2 & 5,6 \\
\hline 42 & The Paleogeographic atlas project & http://pgap.uchicago.edul & 3 & 3 & 3 & 1 & 2 & 1 & 1 & 4 & 0 & 2 & 5,6 \\
\hline 43 & Departamento de Petrologia e Metalogenia & http://jade. igce.unesp.br/ & 2 & 2 & 3 & 2 & 2 & 1 & 3 & 2 & 2 & 2 & 5,5 \\
\hline 44 & Investigando a Terra - IAG - USP & http://www.iag.usp.br/siae98/ & 4 & 4 & 3 & 1 & 2 & 1 & 0 & 3 & 0 & 2 & 5,5 \\
\hline 45 & Mineralogy Database & http://webmineral.com/ & 3 & 3 & 3 & 1 & 2 & 1 & 2 & 3 & 0 & 2 & 5,5 \\
\hline 46 & Geological Science - Geochemistry & http://www.geo.cornell.edu/geology/classes/geo455/Geo455.html & 2 & 3 & 4 & 1 & 1 & 1 & 3 & 4 & 0 & 1 & 5,5 \\
\hline 47 & Portal dos Recursos Minerais & http://www4.prossiga.br/recursosminerais/ & 3 & 3 & 4 & 2 & 1 & 1 & 4 & 1 & 0 & 2 & 5,5 \\
\hline 48 & Geologia BR & http://www.geologiabrasil.hpg.ig.com.br/index.htm & 3 & 3 & 2 & 1 & 2 & 0 & 2 & 2 & 3 & 2 & 5,3 \\
\hline 49 & Observatório Sismológico da Universidade de Brasilia & http://www.obsis.unb.brl & 3 & 3 & 4 & 1 & 1 & 0 & 0 & 4 & 0 & 2 & 5,3 \\
\hline 50 & PMTCRH - Progr. de Monit. de Tempo, Clima e Rec. Hidricos & http://www.cptec.inpe.br/ ppmtcrh/nova/oficial/html/index.html & 3 & 2 & 3 & 1 & 1 & 1 & 1 & 3 & 2 & 2 & 5,2 \\
\hline 51 & CESOL-HP - Celso Eduardo Sobreira Leite & http://www.geocities.com/cesol999/ & 3 & 2 & 4 & 1 & 1 & 0 & 0 & 3 & 2 & 2 & 5,2 \\
\hline 52 & Meio Ambiente e Ciências Atmosféricas & http://www3.cptec.inpe.br/ ensinop/ & 2 & 3 & 3 & 1 & 1 & 0 & 2 & 4 & 0 & 2 & 5,2 \\
\hline 53 & Tempo Geológico & http://www.labgis.ueri.br/geologia/dgrg/webdgrg/Timescale/inicial.htm & 3 & 3 & 4 & 2 & 2 & 0 & 1 & 2 & 0 & 2 & 5,2 \\
\hline 54 & Terra Planeta Vivo & http://domingos.home.sapo.pt/index.html & 3 & 3 & 3 & 3 & 2 & 0 & 2 & 2 & 0 & 2 & 5,2 \\
\hline 55 & Geologia Ambiental - UPOP & http://www.degeo.ufop.br/Portugues/ambiental/index.htm & 3 & 4 & 4 & 1 & 1 & 1 & 0 & 4 & 0 & 1 & 5,2 \\
\hline 56 & DinoData & http://www.dinodata.net/ & 3 & 3 & 3 & 2 & 2 & 1 & 2 & 3 & 0 & 1 & 5,1 \\
\hline 57 & Learning From the Fossil Record & http://www.ucmp.berkeley.edu/fosrec/fosrec.html & 2 & 2 & 3 & 2 & 2 & 1 & 0 & 3 & 0 & 3 & 5,1 \\
\hline 58 & The Sun, a multimedia tour - O Sol, uma viagem multimidia & http://www.michielb.nl/od95/ & 1 & 4 & 3 & 1 & 3 & 2 & 0 & 3 & 0 & 2 & 5,1 \\
\hline 59 & LBA - Experimento de Grande Escala da Biosfera-Atmosfera & http://lba.cptec.inpe.br/lbal & 2 & 3 & 2 & 1 & 1 & 1 & 1 & 4 & 1 & 2 & 5,0 \\
\hline 60 & Estudar os vulcões - Conhecer a Terra & http://www.eps-dr-correia-mateus.rcts.pt/introducao.html & 3 & 2 & 3 & 1 & 2 & 0 & 2 & 2 & 1 & 2 & 5,0 \\
\hline 61 & ENGEO - Geologia e Geofisica & http://www.engeo.com.br/ & 3 & 3 & 3 & 1 & 1 & 0 & 2 & 4 & 0 & 1 & 5,0 \\
\hline 62 & Departamento de Geologia Aplicada - Unesp & http://www.rc.unesp.brligce/aplicadal & 3 & 3 & 3 & 2 & 1 & 2 & 0 & 4 & 0 & 1 & 4,9 \\
\hline 63 & Território dos Dinossauros & http://www.territoriodosdinossauros.hpg.ig.com.br/ & 3 & 2 & 4 & 1 & 2 & 1 & 1 & 3 & 0 & 1 & 4,9 \\
\hline 64 & História da Terra & http://www.geocities.com/historiadaterra/ & 2 & 3 & 3 & 1 & 1 & 1 & 3 & 2 & 0 & 2 & 4,9 \\
\hline 65 & Dinossauria on-line & http://www.dinosauria.com/ & 3 & 3 & 4 & 1 & 1 & 1 & 1 & 3 & 0 & 1 & 4,9 \\
\hline 66 & The Geological Evolution of the Earth & http://www.handprint.com/PS/GEO/geoevo.html & 3 & 3 & 3 & 1 & 1 & 0 & 1 & 3 & 0 & 2 & 4,9 \\
\hline 67 & Rede das Águas & http://www.rededasaguas.org.br/ & 3 & 3 & 2 & 1 & 1 & 0 & 2 & 3 & 2 & 1 & 4,8 \\
\hline 68 & Home-page de Akihisa Motoki - UERJ & http://www.motoki.hpg.ig.com.br/ & 2 & 3 & 3 & 2 & 2 & 1 & 0 & 4 & 0 & 1 & 4,8 \\
\hline 69 & An Introduction to Earth System Science & http://www.geosci.unc.edu/classes/Geo15/G15.html & 3 & 2 & 2 & 2 & 3 & 1 & 1 & 2 & 0 & 2 & 4,7 \\
\hline 70 & Historical Geology & http://gpc.edu/ pgore/geology/historical lecture/historical outline.php & 3 & 3 & 3 & 2 & 1 & 0 & 1 & 2 & 0 & 2 & 4,7 \\
\hline 71 & Earth \& Space Science & http://gpc.edu/ pgore/Earth\&Space/contents.html & 3 & 2 & 3 & 4 & 1 & 0 & 1 & 2 & 0 & 2 & 4,7 \\
\hline 72 & Geologia do Petróleo & http://geocities.yahoo.com.br/geologiadopetroleol & 3 & 4 & 3 & 1 & 1 & 0 & 1 & 3 & 0 & 1 & 4,7 \\
\hline 73 & Geology's Hp & http://www.geology.hpg.ig.com.br/index.html & 3 & 3 & 2 & 1 & 1 & 0 & 2 & 3 & 1 & 1 & 4,5 \\
\hline 74 & Gems e Gem Minerals - University of Texas at Austin & http://www.geo.utexas.edu/courses/347k/index.html & 3 & 3 & 3 & 1 & 1 & 1 & 1 & 3 & 0 & 1 & 4,5 \\
\hline 75 & Geology Wing - University of California & http://www.ucmp.berkeley.edu/exhibit/geology.html & 2 & 3 & 3 & 2 & 2 & 2 & 0 & 3 & 0 & 1 & 4,5 \\
\hline 76 & Tectônica de Placas & http://www.terravista.pt/copacabana/1519/tectonica/ & 2 & 3 & 2 & 1 & 2 & 0 & 1 & 3 & 0 & 2 & 4,5 \\
\hline 77 & Atlas Mineralógico WEBMineral & http://webmineral.brgm.fr:8003/mineraux/Main.html & 2 & 3 & 4 & 1 & 1 & 1 & 0 & 3 & 0 & 1 & 4,4 \\
\hline 78 & GEOTRAK - Portal Geológico & http://www.geotrack.hpg.ig.com.br/index.html & 1 & 3 & 3 & 2 & 2 & 1 & 4 & 1 & 0 & 1 & 4,4 \\
\hline 79 & Animação Gondwana & http://kartoweb.itc.nl/gondwana/index.asp & 2 & 2 & 2 & 1 & 2 & 3 & 2 & 3 & 0 & 1 & 4,4 \\
\hline 80 & Introduction to Petrology & http://www. science.ubc.ca/ qgeol202/ & 3 & 3 & 3 & 1 & 1 & 1 & 0 & 2 & 0 & 2 & 4,4 \\
\hline 81 & Fator Gis - Geotecnologias & http://www.fatorgis.com.br/ & 2 & 3 & 3 & 1 & 1 & 1 & 3 & 2 & 0 & 1 & 4,4 \\
\hline 82 & Earth Materials & http://www.uoregon.edu/ jirice/geol 311/geol 311.html & 2 & 2 & 3 & 1 & 1 & 0 & 1 & 3 & 0 & 2 & 4,4 \\
\hline 83 & Informaçōes Geológicas & http://www.ige.unicamp.br/ adilson/adilson.htm & 1 & 2 & 2 & 3 & 1 & 0 & 2 & 3 & 0 & 2 & 4,3 \\
\hline 84 & Biblioteca Virtual de Engenharia de Petróleo & http://www4.prossiga.br/dep-fem-unicamp/petroleo/ & 2 & 3 & 4 & 1 & 1 & 1 & 4 & 1 & 0 & 0 & 4,2 \\
\hline 85 & Rod Holcombe - Structural Geologist & http://www.earthsciences.uq.edu.au/ rodh/index.html & 2 & 2 & 2 & 1 & 2 & 1 & 2 & 2 & 1 & 1 & 4,1 \\
\hline 86 & Atlas of Rocks, Minerals and Textures & http://www.geolab.unc.edu/Petunia/lgMetAtlas/mainmenu.html & 2 & 3 & 3 & 1 & 1 & 1 & 0 & 3 & 0 & 1 & 4,1 \\
\hline 87 & The Structural Page - por John W. F. Waldron & http://www.stmarys.ca/academic/science/geology/structural & 2 & 2 & 2 & 2 & 1 & 1 & 2 & 3 & 0 & 1 & 4,1 \\
\hline 88 & Estruturas Sedimentares - Mario Carvalho & http://www.geocities.com/mpcarvalho 3000/index.estrut.htm & 3 & 3 & 3 & 1 & 1 & 0 & 1 & 2 & 0 & 1 & 4,1 \\
\hline 89 & Astrosoft & http://nautilus.fis.uc.pt/astro/ & 2 & 3 & 2 & 1 & 1 & 1 & 1 & 2 & 0 & 1 & 3,6 \\
\hline 90 & Geologia Geral & http://geocities.yahoo.com.br/csgeologia/ & 2 & 3 & 2 & 1 & 1 & 0 & 0 & 2 & 0 & 1 & 3,3 \\
\hline \multirow[t]{2}{*}{91} & Rochas e Minerais & http://mineraiserochas.cjb.net/ & 2 & 2 & 2 & 1 & 1 & 0 & 0 & 2 & 0 & 1 & 3,1 \\
\hline & & Gabarito & 4 & 4 & 4 & 4 & 4 & 4 & 4 & 4 & 4 & 4 & 10,0 \\
\hline
\end{tabular}




\section{DESENVOLVIMENTO DE WEBSITE EDUCACIONAL}

O desenvolvimento de websites pode ter duas vertentes principais baseadas nos objetivos pretendidos. Pode-se utilizar a atividade como ferramenta pedagógica fundamentada no construtivismo, ou seja, situação em que o aluno constrói o próprio conhecimento. Quando o aprendiz constrói sua própria página, ele deve organizar toda a estrutura, as informações que pretende expor, o modo de exibição etc. Outra vertente refere-se a disseminar informações de caráter educativo, de modo a instigar a curiosidade dos alunos e auxiliar a tarefa dos educadores, suprindo-os de recursos didáticos sobre temas abordados de forma menos eficiente por outros meios cujo dinamismo é diferente. Este trabalho trata com mais detalhe a segunda vertente, procurando abranger as principais características voltadas para o melhor aproveitamento de websites educacionais com o fim de disponibilizar informações e aumentar o interesse dos temas cobertos pelas Geociências, que podem ser aproveitados em disciplinas dos níveis de ensino fundamental e médio (principalmente Ciências e Geografia).

Desenvolver websites requer várias atividades sucessivas, como geração de idéias, planejamento, coleta e organização de materiais a serem disponibilizados, conhecimento de linguagens específicas e percepção visual, entre outras. Toda a criação de um website deve manter o foco nas informações e no usuário. Deve proporcionar a organização das informações de forma a torná-las facilmente acessíveis e privilegiar uma estrutura intuitiva, na qual o usuário possa, em uma rápida visita, obter uma visão geral do conteúdo abordado. Tal objetivo pode ser alcançado utilizando um menu principal bem estruturado, com os temas divididos em subgrupos, de forma padronizada e evitando-se links dispersos.

\section{Definição e análise do material a ser disponibilizado}

A definição dos objetivos é a primeira etapa de um projeto de desenvolvimento de website. Ela requer a especificação do tipo de material que se pretende expor, o impacto que se pretende causar, e principalmente o tipo de usuário que será o público-alvo do projeto. Enfim, são os pontos focais que influenciarão a definição de estratégias de desenvolvimento e exposição do material educacional. Outro passo importante na elaboração de websites educacionais é o levantamento e seleção de informações. Essa é uma etapa que deve ser seguida com critérios de qualidade bem determinados, ou seja, o conteúdo a ser disponibilizado deve ser bem fundamentado e livre de todo tipo de imprecisão. A exposição deve ser clara e agradável, se possível bem ilustrada e com a utilização de ferramentas multimídia que enriqueçam o resultado final.

\section{Abordagem pedagógica e forma de exposição}

Esta etapa refere-se à estratégia educacional a ser aplicada, bem como as formas pelas quais o conteúdo estará disponível ao usuário. Tais decisões certamente dependerão das diretrizes iniciais do perfil do usuário-alvo e os objetivos instrucionais, que são as habilidades e conhecimentos a serem adquiridos por meio da utilização do website ou software educacional.

Se os usuários principais são educadores e a função do website é disponibilizar recursos para enriquecer as aulas, o conteúdo deve estar disposto de forma a permitir adaptações de acordo com a necessidade do usuário, além de contar com sugestões de atividades e formatos de exposição que possam ser utilizados em aulas. No caso em que o público-alvo são alunos e aprendizes, o website deve privilegiar a interatividade e valorização do conteúdo. Tal objetivo pode ser atingido por meio da utilização de ferramentas multimídia, como aplicativos (p. ex.: no website http://kartoweb.itc.nl/gondwana/index.asp) ou, ainda, aproximando o conteúdo didático do usuário ao serem abordados conceitos regionais ou ao serem utilizados exemplos práticos. Pode-se ainda estruturar uma forma de apresentação não-linear, com hipertextos que permitam um relativo controle do usuário sobre o próprio aprendizado, seguindo o seu próprio ritmo. Além disso, existem mecanismos que também podem ser utilizados, como é o caso de sistemas de "Pergunte a um especialista" ou fóruns de discussão.

O website deve conter uma estrutura na qual as informações sejam separadas em blocos organizados por seções, que permitam a fácil navegação e rápida localização do conteúdo desejado.

"O designer deve se esforçar para que o usuário facilmente crie um modelo mental do site, a fim de que a navegação seja intuitiva, permitindo um rápido acesso às informações” (Oliveira, 1995, p. 38).

Bons exemplos de abordagem pedagógica e de utilização de recursos disponíveis para exposição do conteúdo podem ser vistos em alguns websites educacionais analisados, que fazem parte do Banco de Dados, como por exemplo:

www.geopor.pt/gne/index.html

www.usgs.gov/education

www.bbc.co.uk/education/rocks 


\section{CONCLUSÕES}

O universo digital de informações na Web mostra-se cada vez mais abrangente, trazendo uma gama de recursos de interessante aplicação nas relações ensino/aprendizagem. Entretanto, devido à vastidão do conteúdo disponível, freqüentemente as informações se perdem no hiperespaço, e a localização pode se tornar uma atividade desgastante e pouco produtiva. Esse fator faz do presente experimento de análise e classificação do universo de 91 websites de Geociências uma referência útil na aplicação pedagógica da Internet. Por outro lado, a pesquisa revelou que a abordagem pedagógica é distinta daquela utilizada em métodos convencionais de ensino, nos quais é baixo o aproveitamento de ferramentas interativas. Também se nota o predomínio de websites que abrangem temas de Geologia Geral e a deficiente abordagem de temas de caráter regional, que pudessem transformar o conteúdo didático em algo mais próximo ao aprendiz e que, provavelmente, facilitariam a construção do conhecimento.

\section{AGRADECIMENTOS}

Os autores agradecem ao Conselho Nacional de Desenvolvimento Científico e Tecnológico (CNPq) por bolsa de produtividade em pesquisa concedida a um deles (CDRC, processo 303208/87-2) e pela bolsa de Iniciação Científica que tornou possível a pesquisa. Agradecem ainda a dois anônimos revisores desta revista, pelas pertinentes sugestões, que muito contribuíram para aprimorar o manuscrito.

\section{REFERÊNCIAS BIBLIOGRÁFICAS}

BRILHA, J. B ; LEGOINHA, P. Internet: uma nova estratégia para o Ensino das Ciências da Terra. In: CONGRESSO NACIONAL DE GEOLOGIA, 5., 1998, Lisboa. Comunicações do Instituto Geológico e Mineiro. Lisboa, 1998. Tomo 84, fasc. 2, H8-H11. Disponível em:

http://www.dct.fct.unl.pt/PLegoinha/IntCNG.html. Acesso em: 11 set. 2003.

BARBOSA, R. Projeto Geo-Escola: recursos computacionais de apoio ao ensino de geociências nos níveis fundamental e médio. 2003. 105 p. Dissertação (Mestrado em Geociências) - Instituto de Geociências, Universidade Estadual de Campinas, Campinas, 2003.

BUTLER, D. M.; MACGREGOR, I. D. Globe: science and education. Journal of Geosciences Education, v. 51, n. 1, p. 9-20, 2003.
CARNEIRO, C. D. R. Lecciones de geociencias apoyadas por las computadoras. In: SIMPOSIO DE LA ENSEÑANZA DE LA GEOLOGÍA, 12., 2002, Girona. Actas... Girona: AEPECT, 2002. Documentos de Trabajo, p. 58-63.

CARNEIRO, C. D. R.; BARBOSA, R. Demandas de conocimiento de geociencias por profesores de Ciencias y Geografía: el ejemplo de Jundiaí-Atibaia. São Paulo, Brasil In: SIMPOSIO DE LA ENSEÑANZA DE LA GEOLOGÍA, 12., 2002, Girona. Actas... Girona:AEPECT, 2002. Documentos de Trabajo, p. 47-57.

CARNEIRO, C. D. R.; BARBOSA, R. Projeto Geo-Escola: materiais didáticos em Geociências com suporte no computador, módulo Jundiaí-Atibaia, Estado de São Paulo. Campinas: Instituto de Geociências. Universidade Estadual de Campinas, 2002b. Disponível em:

http://www.ige.unicamp.br/ jundiati/. Acesso em: 15 fev. 2005.

FERRÉS, J. Guía para la navegación por Internet. Enseñanza de las Ciencias de la Tierra, v. 10, n. 1, p. 73-77, 2002.

FIGUEIREDO, J. Importância da Internet para o ensino/ aprendizagem de Geologia. Disponível em:

http://www.uc.pt/cienterra/ect/2003ResCursoAPGp17-21.pdf. Acesso em: 11 set. 2003.

GALLAGHER, M. Geoscience software reviews. Journal of Geosciences Education, v. 48, p. 210-211, 2000a.

GALLAGHER, M. Geoscience software reviews. Journal of Geosciences Education, v. 48, p. 555-557, 2000 b.

GALLAGHER, M. Geoscience software reviews: portrait USA American Geological Institute. Journal of Geosciences Education, v. 48, p. 720-721, 2000c.

GORE, P. J. W. Using the World-Wide Web in the geology classroom. Journal of Geosciences Education, v. 45, p. 246-251, 1997.

HEIDE, A. Guia do professor para a Internet: completo e fácil. Porto Alegre: Artes Médicas Sul, 2000. 337 p.

HUNTOON, J. E.; RIDKY, R. K. Examining long-term global climate change on the web. Journal of Geosciences Education, v. 50, n. 5, p. 497-514, 2002.

KUSNICK, J. The Strategy Column for precollege teachers: thinking about computer-based learning. Journal of 
Geosciences Education, v. 49, n. 2, p. 212-214, 2001.

MACEDO, M. Do texto ao hipertexto. In: MASSARANI, L.; MOREIRA, I. C.; BRITO, F. (Org.). Ciência e público: caminhos da divulgação científica no Brasil. Rio de Janeiro: Casa da Ciência. Centro Cultural de Ciência e Tecnologia da UFRJ, 2002. (Série Terra Incógnita).

MACHADO, A. A. Análise de sites em Geociências e difusão de materiais didáticos na Internet sobre a região de Jundiaí-Atibaia. 2002. Relatório (Iniciação Científica) Instituto de Geociências, Universidade Estadual de Campinas, Campinas, 2002.

MEDEIROS FILHO, D. A.; CINTRA, J. P. Desenvolvimento de software para o ensino e aprendizagem. S.l.: s.n., 1999. Disponível em: http://www2.insoft.softex.br/ scie/1999/ DanteARibeiroFilho-DesenvolvimentoAprendizagem.html. Acesso em: 11 set. 2003.

MEIRA, L. Reflexões sobre aprendizagem e ensino na Internet. Recife: Universidade Federal de Pernambuco. Instituto de Psicologia, 2002. 7 p. Disponível em:

http://www.ufpe.br/psicologia/luciano 21.htm. Acesso em: 14 maio 2004.

OLIVEIRA, O. L. Design de ambientes computacionais para modelagem em um contexto educacional. 1995. Dissertação (Mestrado) - Instituto de Matemática, Estatística e Computação Científica, Universidade Estadual de Campinas, Campinas, 1995.

OTSUKA, J. L. Fatores determinantes na efetividade de ferramentas de comunicação mediada por computador no ensino à distância. S.l.: Universidade Federal do Rio Grande do Sul. Instituto de Informática, 1999. T.I. nº 619 CPGCCUFRGS. Disponível em:

http://penta.ufrgs.br/pesquisa/joice/joice ti.html\#sumula. Acesso em: 11 set. 2003.

PACHECO, S. B. Internet: as relações de ensinoaprendizagem no hiperespaço. Tecnologia Educacional, v. 25, n. 136-137, p. 15-19, 1997.

REZENDE, L.; JESUS, C. A. Desenvolvendo site educacional na Web. In: INFO EDUCAR-FÓRUM DE INFORMÁTICA EDUCATIVA, 4, 1999. Disponível em:

http://www2.insoft.softex.br/ scie/1999/LuizianaRezendeDesenvolvendoSiteEducacionalNaWeb.html. Acesso em: 11 set. 2003.

ROCHA, H. V. Educação à distância. In: SEMINÁRIO
NACIONAL SOBRE CURSOS DE GRADUAÇÃO EM GEOLOGIA, 2., 2002, Campinas. Campinas: Unicamp. Instituto de Geociências, s.d. 12 p. Apresentação inédita do software Teleduc. Disponível em: http://www.ige.unicamp.br/ jundiati/.

VALENTE, J. A. Computadores e conhecimento: repensando a educação. Campinas: Unicamp, 1993. 418 p. 